\title{
MARCAS ENTOACIONAIS NA AQUISIÇÃO DA LINGUAGEM INFANTIL
}

\section{Ana Lúcia Leal ${ }^{(*)}$ \& Marígia Ana de Moura Viana ${ }^{(* * *)}$}

Sem o tom as palavras ficam irremediavelmente mutiladas.

Mattoso Câmara Jr.

Resumo: Este estudo tem como finalidade investigar a emergência e o desenvolvimento das marcas entoacionais na aquisição da linguagem infantil dentro de um contexto interativo. O pressuposto utilizado é o de que as escolhas tonais, que vão sendo feitas ao longo da interação. são responsáveis pela construção de um "contexto": as opções tonais vão construindo o sentido do texto simultaneamente. Ou seja, o contexto interativo implica o reconhecimento de que o comportamento prosódico do falante constrói um contorno entoacional significativo.

O trabalho dissertativo, em andamento, apresenta uma discussão sobre a emergência e o desenvolvimento das marcas entoacionais da linguagem infantil e tenta contribuir para um conhecimento mais abrangente relativo ao processo de aquisição da linguagem. Destaca-se, ainda, a consideração dada ao contexto interativo vivido pelos sujeitos ao longo de todo o período de análise.

Espera-se contribuir para os estudos sobre como se estruturam os padrões entoacionais nos dois primeiros anos de vida e quais destes padrões são modificados ou mantidos ao longo desta fase. Existe a intenção de se verificar como estas pistas entoacionais revelam a troca comunicativa dentro de um contexto interativo.

Palavras-chave: Padrões entoacionais; aquisição da linguagem: criança; desenvolvimento; interação

(*) Fonoaudióloga e Psicóloga pela Universidade Católica de Pernambuco, Especialista em Voz pelo Centro de Estudos em Fonoaudiologia Clínica. Professora e Coordenadora da Clínica-Escola de Fonoaudiologia da Faculdade Integrada do Recife, Professora convidada do Curso de Especialização em Linguagem pela Universidade Federal de Pernambuco.

(*) Professora Doutora do Departamento de Psicologia da Universidade Católica de Pernambuco e Coordenadora do Programa de Mestrado em Ciências da Linguagem da Universidade Católica de Pernambuco. 
Desde o início de sua existência, o homem está envolvido num intrincado e complexo processo de aquisição de regras comunicativas, porém, muitas vezes com uma mínima noção do que representa o conjunto de procedimentos presentes na comunicação humana.

Atualmente, a concepção de linguagem mais adotada, discutida e difundida nos meios acadêmicos e científicos, pressupõe, necessariamente, a existência de fatores lingüísticos, psicológicos e
interacionais.

Como diz Viana (2000), o fator lingüístico, como o próprio termo sugere, refere-se aos elementos relativos à organização do discurso, às regras que ordenam e permitem o compartilhamento do
código.

O aspecto psicológico representa o conhecimento acumulado,
resultado de experiências e vivências, também chamado de conhecimento enciclopédico. Este aspecto está relacionado ao modo como cada um interpreta e se relaciona com os fatos do mundo, sendo possível, a partir dele, a formação de conceitos e generalizações. Destaca-se a compreensão de que os fenômenos psicológicos englobam não só os aspectos conscientes, mas também os inconscientes. Sendo assim, é necessário observar, por parte dos falantes (consciente e inconscientemente), as regras a serem seguidas se quiserem ser entendidos numa conversação.

O terceiro aspecto, o interacional, está diretamente ligado aos outros dois e constitui a própria realização do discurso, tornando possível a construção do sentido. Este aspecto representa uma condição essencial à própria existência da linguagem, já que ela se constitui, se realiza e se atualiza na e pela relação dialógica. A atividade interacional, portanto, constitui e ao mesmo tempo resulta da atividade comunicativa verbal, que por sua vez é estratégica e intencional. Neste sentido, será no processo de inter-ação com o outro que o texto verbal vai sendo, gradativamente, elaborado, revisto e atualizado.

A interação verbal abrange não só os aspectos linguiísticos (onde incluo os suprassegmentares) e paralinguísticos (gestos, mímicas, olhar, etc.), mas envolve a situação em que os participantes estão inseridos, as influências sociais e psicológicas, as relaçōes que 
se estabelecem entre o falante e o ouvinte num espaço discursivo em que cada um assume um papel no curso da interação.

Estes papéis só têm significação no âmbito das relações interpessoais, onde o comportamento lingüístico de um influencia o do outro. Faz-se indispensável que a interação seja encarada como um processo dinâmico, advinda das relações que se estabelecem entre os participantes no conjunto dos atos comunicativos.

A análise do diálogo infantil pressupõe que o pesquisador se interrogue sobre como a criança se comporta no curso de uma interação, ou seja, como retoma, modifica, suprime ou acrescenta elementos no desenvolvimento de um tema, qual o papel que assume na relação com seus interlocutores e quais estratégias discursivas que utiliza no curso da interação. Além disso, é primordial reconhecer e legitimar o efeito do interlocutor como participante direto da construção e desconstrução da troca comunicativa.

Destacando a importância, para a aquisição da linguagem, das primeiras trocas entre o bebê e quem exerce a função materna, é possível utilizar a reflexão de Vorcaro (2001, p.275), quando diz que

o agente materno toma as manifestações orgânicas como marcas lidas como mensagem, apagadas pela resposta oferecida e balizadas por precauções que as evitem. As manifestações vitais são tomadas como signos, marcas que representam um ser para alguém. Portanto, a resposta do agente materno às manifestações do organismo é imposição que sobre-determina a inserção do ser no campo da linguagem.

Felizmente, na atualidade, as investigações lingüísticas têm se voltado à análise dos fenômenos conversacionais e é inquestionável a importância da a mãe no desenvolvimento da linguagem do bebê. De acordo com Viana (2000, p. 35-44), cada cultura apresenta formas distintas para lidar com a realidade de aquisição da linguagem da criança. Em algumas culturas, há uma intervenção mais direta dos pais, participando e interagindo com a criança, buscando identificar as relações entre a intenção da criança e diferentes situações, através do processo de reformulação. Já em outras, há uma forma de participação muito limitada, não reconhecendo que, identificada à intenção, a criança estará, de fato, produzindo enunciados próprios, ou seja, atuando como parceiro na interação e, dessa forma, comunicando-se, 
assumindo o papel de interlocutor. O mesmo autor aponta que, nas comunidades em que o bebê é visto como interlocutor, como autor de suas mensagens, em que a intenção é vista como o objetivo da enunciação, ele passa a ser considerado destinatário, mesmo ainda durante a fase de gestos e vocalizações que precedem a produção de palavras reconhecidas como formas lingüísticas elaboradas na forma de palavras reconhecíveis na língua do adulto (VIANA, 2000, p.38).

Cavalcante (2001, p.585) realizou um interessante trabalho, inicialmente aprofundado em sua tese de doutorado (1999), sobre o tema em questão. A autora referiu que a fala materna dirigida ao bebê, denominada de manhês, se caracteriza por apresentar clareza, brevidade, graus de repetitividade e de simplificação, aliadas a modificações prosódicas como: freqüência fundamental mais alta, âmbito de altura maior, preferência por certos contornos (sobretudo os tons ascendentes), uso de falsetto, cadência mais lenta, partes sussurradas do enunciado, duração prolongada de certas palavras, mais de uma acento frasal, etc.

Cavalcante (2001) comenta que os estudos neodarwinistas têm se dedicado às marcas prosódicas desta fala, principalmente às curvas entoacionais produzidas em situações afetivas (aprovação, proibição, conforto e atenção), todas possuidoras de traços universais, na linguagem de Fernald (1993, apud CAVALCANTE, 2001). A função atribuída a tais melodias "universais", explicitada num modelo desenvolvido por Fernald, é a de estimular estados de alerta, prazer, conforto, etc.; aos poucos, essas vocalizações maternas vão modulando a atenção e a emoção do infante, dando pistas das intenções e estados emocionais dos outros. E, finalmente, a saliência de certas marcas prosódicas no manhês possibilitariam a identificação de unidades lingüísticas pela criança" (ibidem, p.585).

Há pelo menos dois tipos de fala atribuída: a interpretativacomportamental e a passível de deriva. A fala do tipo interpretativocomportamental apresenta-se predominantemente nas situações de conforto, onde a qualidade de voz e o tipo de curva entoacional são: voz sussurrada com alongamento e curvas descendentes para o conforto e voz em falsetto com curvas ascendentes para a interação positiva. Na fala passível de deriva, predominam curvas descendentes, VOZ em falsetto e infantilizada, velocidade de fala rápida para a negação/rejeição (CAVALCANTE, 2001, p.558): 
ao longo de tempo, a fala atribuída, ou como se, vai assumindo uma estrutura diferenciada. Sua frequiência é maior nos primeiros meses e vai diminuindo a partir do sexto mês até assumir uma estrutura prosódica nova ao final do oitavo/nono mês, para então extinguir-se. Esta trajetória acompanha o desenvolvimento vocal do bebê. da total indeterminação comunicativa, para, aos poucos tornar-se mais presente na interação, assumindo seus próprios turnos.

Sendo assim, na interação face a face, quem ouve tem acesso tanto à forma do que é dito quanto ao modo como o dito é enunciado dentro de um contexto interacional útil para sanar/evitar problemas de compreensão. Admite-se que é possível distinguir o dito do que se quis dizer, concebendo-se uma compreensão do conteúdo implícito que todo e qualquer texto traz.

A apreensão das intenções que se inscrevem no enunciado é fundamental à compreensão do texto, sendo assim, é necessário considerá-lo não apenas como um artefato lingüístico bem organizado, mas também como um evento comunicativo socialmente relevante, que se realiza (atualiza) na interação. Considera-se, nessa perspectiva, o produtor e o receptor do ato de linguagem envolvidos em uma atividade complexa, composta não apenas por fenômenos lingüísticos, mas também antropológicos e sociais.

Para Luciano (2000), a expressividade resultará do modo como o dito é elaborado dentro de um processo interativo de construção de sentido, observável precisamente quando restituímos "voz" ao texto.

Os padrões expressivos são caracterizados pelos aspectos prosódicos, tais como a segmentação, o ritmo e a ênfase. Estes, em muito contribuem para a construção de sentido e, atrelados a elementos da melodia da fala (entoação), transformam-se em marcas explícitas de intencionalidade. Sendo assim, é possível dizer que a expressividade na fala é um comportamento prosódico natural, espontâneo e intencional.

Nos diálogos infantis, constata-se que "as repetições de segmentos fônicos ou de esquemas entoacionais marcam a presença do ludismo, quando as crianças jogam com as palavras, independentemente de seus eventuais significados" (François et al., 1984, p.147, apud AZEVEDO, 1997, p.29). 
Para Veras (2001, p.286), a criança fala primeiro improvisando, nessa língua, o balanço pelo qual se deixa levar mas, "pouco a pouco uma partitura se impõe, dando ao improviso uma tonalidade, que poderá dar lugar às dissonâncias em que sua fala, vez por outra, permitir-lhe-á assinar sua criação, selando-a com a marca idiomática”.

Luciano (2000) acredita que a expressividade se manifesta pelas marcas lingüísticas segmentais e suprassegmentais decorrentes da interação entre os interactantes e o próprio enunciado. E, por isto. é necessário observar que tipo de implicações as marcas prosódicas trazem para a compreensão do ouvinte.

Parafraseando Dondis (1991, apud LUCIANO, 2000, p.30) sobre a importância da luz e do tom (cores) para a composição visual, pode-se dizer que "os segmentos e os suprassegmentos são os meios pelos quais distinguimos auditivamente a complexidade da informação textual numa situação comunicativa".

Sendo assim, ao se observar as falas do cotidiano, é perceptivel a qualquer indivíduo a riqueza melódica e rítmica na voz humana, com implicações diretas para os significados produzidos na interação. Os contornos altos e baixos, as acelerações e desacelerações, as cadências marcadas, os alongamentos silábicos ou vocálicos, as proeminências (saliências fônicas) e as variações do eixo melódico, revelam a fala, que é constituída, de um lado pelo sistema e, de outro, pelas interações comunicativas, reveladas também por meio desses recursos audíveis.

É interessante destacar, que esta fragmentação acusticamente inteligível, ao invés de promover uma descontinuidade no fluxo informacional, produz, no jogo do contínuo/descontínuo, os efeitos de sentido fundamentais à compreensão dos interlocutores.

Um outro aspecto suprassegmental merecedor de importância diz respeito ao ritmo. Recusa-se a concepção tradicional de ritmo definido unicamente por meio do jogo acentual ou saliências fônicas e assume-se uma perspectiva discursiva que extrapola os limites da fonética. Os elementos melódicos e rítmicos constituem, então, os aspectos da dimensão sonora da elocução, onde a inflexão da voz valoriza determinados itens ou conjuntos de itens, distinguindo significações. 
David Brazil (1978) aponta que a entoação representa uma das estratégias do falante para orientar o ouvinte a apreender o significado comunicativo dos enunciados. Para ele, o padrão entoacional na fala de qualquer indivíduo mantém uma relação direta com sua intenção comunicativa.

Destaca-se que além da entoação poder ser encarada como uma estratégia consciente do falante, é interessante também considerar os aspectos inconscientes, que interferem na construção do ato intencional, momentos estes em que o falante é atravessado, a sua revelia, por impressões até então não reconhecíveis e, no entanto, reveladas involuntariamente, no encontro da troca dialógica.

Brazil (1978) abordou os conceitos de orientação oblíqua e direta do discurso. Na orientação oblíqua do discurso, o falante
assume o papel de mero sonorizador das palavras, sem dar relevo às estratégias interacionais, sem conseguir atribuir a força ilocutória' adequada. O discurso oblíquo centra-se na língua em sua superfície, não se direcionando a um destinatário, reduzindo o valor comunicativo das unidades tonais ali contidas e promovendo um distanciamento do ouvinte pela ausência do fenômeno vulgarmente chamado de naturalidade na fala. Neste tipo de discurso, há apenas dois tons: um descendente (fall), para os pontos de completude sintática, e um outro no nível (level), neutro, nem ascendente nem descendente, para todas as outras situações.

Em contrapartida, no discurso de orientação direta, centrado no conteúdo, há uma preocupação direta com o ouvinte. Neste caso, a diversidade de tons é maior, bem como a diferença em níveis tonais, emprestando à fala um "colorido" tipicamente natural. Este autor descreve cinco tons para esse tipo de discurso. São eles:

- Dois tons ascendentes, chamados tons alusivos $\left(\mathrm{r}^{\mathrm{e} \mathrm{r}^{+}}\right)$;

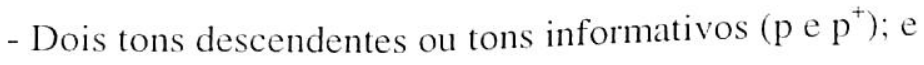

- Um tom neutro ou no nível (o).

O tom ascendente $\mathbf{r}$ é considerado tom dominante. Distinguese do tom $\mathbf{r}^{+}$porque, no dominante, há uma descendência anterior à subida no tom $(\backslash \lambda)$.

Força ilocutória: diz respeito à função dos suprassegmentos dentro do discurso. 
$\mathrm{O} \mathbf{r}^{+}$é apenas brevemente ascendente $(\nearrow)$. No tom descendente dominante $\mathbf{p}^{+}$, há uma breve ascendência antes da queda tonal $(/ \searrow)$, diferentemente da descendência característica do tom $\mathbf{p}(\searrow)$.

A cada um desses tons são atribuídos valores comunicativos de natureza informativa ou interacional. Os tons descendentes recaem sobre elementos considerados pelo falante como informação nova, ficando os tons ascendentes para as alusões a conteúdos partilhados pelos interactantes, servindo de ancoragem textual para os conhecimentos novos.

Esses tons são relacionados à intenção do falante pela observação das funções interacionais que podem assumir. Podem ser: a) informar ao ouvinte quanto à natureza do que é dito; b) informar em que ponto o ouvinte pode cooperar; c) informar como a cooperação pode ser dada; d) avaliar a contribuição do ouvinte; e tantos outros aspectos definidos situativamente numa relação do tratamento entoacional com o contexto de interação.

Luciano (2000, p.70) destaca que essas funções podem ser resumidas a uma tríade funcional exercida pela entoação, observável em qualquer interação. São elas: (1) a função organizacional; (2) a função social; e (3) a função informativa, propriamente dita.

A primeira função, a organizacional, diz respeito a como os tons são usados pelo falante para organizar o discurso e, para Brazil, é provável haver a consciência desse aspecto por parte dos interactantes. É válido ressaltar que "ser provável" não significa uma única possibilidade e que, portanto, é possível, mais uma vez, recorrer à compreensão de que há elementos inconscientes que permeiam os discursos.

A funçāo social requer que os indivíduos conheçam o seu papel dentro daquela estrutura organizacional. É percebida através das pistas entoacionais fornecidas pelos falantes para terem os seus papéis assegurados na interação.

Na função informativa, há o reconhecimento de pistas entoacionais orientadoras da construção de sentido pelo interlocutor, sinalizando as proposições mais relevantes.

Para a construção de sentido, na perspectiva pragmáticia, considera-se a noção de contexto interativo resultante da enunciação, ou seja, não são os aspectos da situação comunicativa que levam ìs 
escolhas de tons pelo falante, mas são as escolhas tonais que vão sendo feitas ao longo da interação que constroem um "contexto", constroem o sentido do texto situativamente.

Em relação a esta perspectiva é essencial esclarecer que a entoação reveza-se, no mesmo sujeito, de acordo com os desdobramentos obtidos nas interações. Ou seja, influenciamos e somos influenciados a partir do contato com o outro e será desse encontro irrepetitível que surgirão novas "pistas" que, por sua vez, determinarão a evolução, ou não, das trocas comunicativas.

Brazil (1985) acredita que a noção de contexto interativo implica no reconhecimento de que o comportamento prosódico do falante constrói um contorno entoacional significativo, pelo fato de ser interpretado pelo ouvinte como constitutivo do conteúdo informacional.

É válido ressaltar que a competência entoacional do outro deve ser legitimamente reconhecida, independentemente do resultado
final da interação. Mesmo que os interactantes desistam de prosseguir em suas trocas dialógicas, suas marcas entoacionais denunciam, mesmo que involuntariamente, a disponibilidade ou não para o contato entre os mesmos e norteiam a direção da comunicação. Neste sentido, é possível concordar que os falantes de fato apresentam um conhecimento das implicações trazidas pelos padrões prosódicos para o discurso.

Sendo assim, compartilha-se da compreensão de Brazil (1985) quando afirma que, quando os usuários estão interagindo por meio da fala, eles segmentam as estruturas não apenas devido à respiração ou às coerções sintáticas. A secção dos enunciados em pequenas unidades se dá com o objetivo de facilitar a compreensão do interlocutor. A estas partes, dá-se o nome de unidades tonais (tone units), utilizadas inicialmente a partir da constatação de que, durante a enunciação, a fala parece ser composta pelo que Crystal (1969, apud LUCIANO, 2000) nomeia jatos de linguagem.

As unidades tonais são planejadas no momento em que o falante vai organizando sua fala, e caracterizam-se por uma subida ou descida no tom, contrariando, assim, o princípio de definição pela segmentação decorrente da força articulatória. Em cada unidade de tom, são fornecidas ao ouvinte pistas de intenção comunicativa do falante. Para tanto, alguns elementos da estrutura sintática são 
selecionados por meio de proeminências, entendidas como a força articulatória atribuída a uma sílaba que se destaca na unidade de tom.

Os diferentes níveis das proeminências são:

a) Baixo: não há intenção de acrescentar e não há expectativa estabelecida;

b) Médio: a intenção é dizer que concorda com o outro. A pista é aditiva e o falante espera concordância do ouvinte.

c) Alto: a intenção é contradizer - implica um julgamento. A pista é contrastiva e oferece ao ouvinte uma chance para contestar.

Tanto a presença quanto a ausência de proeminências são significativas para o enunciado e podem, inclusive, revelar a dinâmica psico-afetiva dos interactantes.

Bennett (1981, apud LUCIANO 2000), ao analisar a conversação, propôs uma teoria da compreensão com base na identificação das funções comunicativas exercidas pelos aspectos prosódicos. Sugerem-se duas dimensões gerais de análise: (a) a dimensão horizontal e (b) a dimensão vertical. $\mathrm{Na}$ dimensão horizontal da prosódia, são observados os efeitos causados pela segmentação em níveis tonais e pela diferença de um grupo para outro em volume (crescendo/decrescendo). É possível dizer que essa dimensão permite ao analista uma macro-visão da prosódia numa direção linear (no discurso).

A dimensão vertical, por sua vez, refere-se à segmentação em unidades tonais, às proeminências e à tonicidade dos grupos tonais. Neste caso, permite-se uma micro-visão bidirecional da prosódia (na cadeia da fala e no discurso). Sendo assim, uma análise do significado da prosódia terá maior validade não só inserido nessas duas dimensões, mas considerando-se ainda a relação existente entre elas.

$\mathrm{Na}$ teoria interacional do tom, Brazil (1985) oferece um aparato teórico-metodológico com vistas a tornar possível a identificação de como a voz vai dando forma aos enunciados, com base nos efeitos semântico-discursivos produzidos por ela.

Dentro dessa linha sócio-interacionista, Gumperz (1982, apud LUCIANO, 2000) propõe que se faça uma análise da entoação a partir da observação do tipo de informação que os falantes confiam à prosódia para manter uma conversa. Propõe a identificação do 
contorno entoacional das falas dos interactantes. Ao defender a tese de que cada dica prosódica não significa nada isoladamente, mas sim dentro de uma estrutura temática coesiva, postula que a entoação irá marcar uma determinada linha de argumento.

Pelo que foi abordado anteriormente, deve estar claro o interesse pelo estudo do tema em questão. Como foi apontado, uma das funções básicas da entoação é a de realçar ou reduzir certas partes do discurso, possibilitando ao interlocutor dar valor e importância a certos elementos e tratar com menos importância outros elementos, fornecendo pistas que possibilitarão a continuidade, ou não, da troca comunicativa.

Para Cagliari (1992), a realização desta função de salientar ou diminuir elementos tem por finalidade relacionar elementos distantes no texto, concatená-los à longa distância, fazer, enfim com que o interlocutor não perca o fio do discurso, a linha argumentativa que se pretende dar ao texto.

Os elementos entoacionais, portanto, não são simples enfeites fonéticos da linguagem oral e servem para ponderar os valores semânticos dos enunciados, sendo uma das formas de que dispõe o falante para dizer ao seu interlocutor como ele deve proceder diante do que ouve.

Se não houvesse um consenso compartilhado entre os usuários da língua a respeito do valor dos elementos prosódicos na linguagem oral, seria possível dizer qualquer enunciado de qualquer modo que a comunicação não se perturbaria nem se alteraria. As reações das pessoas, no entanto, demonstram que compartilhamos dos valores prosódicos de maneira semelhante à que usamos para os demais fenômenos da linguagem humana.

Analisar, portanto, como surgem as marcas entoacionais na aquisição da linguagem infantil e quais destes padrões são mantidos ou modificados ao longo dos primeiros dezoito meses de vida, dentro de um contexto interativo, não é um trabalho simples, mas também não é uma obra impossível. Pelo contrário, esse estudo não só é viável, como necessário ao conhecimento da emergência da entoação, possibitando articular o padrão entoacional da fala do bebê e de sua mãe, à intenção comunicativa que irá, a cada momento, ser construída na e pela relação dialógica. 


\section{Referências bibliográficas}

AZEVEDO, J. A. M. de. Aspectos da conversação infantil: organização tópica, argumentação e relação interpessoal. 1997, 143 f. Dissertação (Mestrado em Letras e Lingüística). Recife: Universidade Federal de Pernambuco - UFPE.

BRAZIL, D. The communicative value of intonation in English. Birmingham: English language Reasearch (discourse Monographs Series, 8), 1985.

BRAZIL, D. Discussing discourse. Birmingham: English Language Reasearch - ELR 1987.

CAGLIARI, L. C. Da importância da prosódia na descrição de fatos gramaticais. In: ILARI, Rodolfo (Org.). Gramática do Português falado. Campinas: Unicamp, 1992, p 39-64.

CAVALCANTE, M. C. B. A fala atribuída: as vozes que circulam na fala materna. Letras Hoje. Porto Alegre. V. 36, n. 3, p. 585-591, 2001.

CAVAlCANTE, M. C. B. Da voz à língua: a prosódia materna e o deslocamento do sujeito na fala dirigida ao bebê. 1999. $230 \mathrm{f}$. Tese (Doutorado em Lingüística). Campinas: Instituto de Estudos da Linguagem da Universidade Estadual de Campinas.

LUCIANO, D. Prosódia e envolvimento na compreensão do telejornal. 2000. 278 f. Tese (Doutorado em Letras e Linguiística). Recife: Universidade Federal de Pernambuco - UFPE.

VERAS, V. A fala da criança e o tempo defasado entre fala e escuta. Porto Alegre: Letras Hoje, V. 36, n. 3, p. 283-288, 2001.

VIANA, M. Padrões entoacionais nos processos de continuidade e descontinuidade na fala. UFPE (mimeo), Recife, 1992.

VIANA, M. O papel da família no processo de aquisição da linguagem. Recife, Revista Symposium. Ano 4. Número especial, p. 35-44, 2000.

VORCARO, A. Incidência da matriz simbolizante no organismo: a advento da fala. Letras Hoje. Porto Alegre. V. 36, n. 3, p. 273-281, 2001. 